\title{
MICROWAVE-ASSISTED MULTI-COMPONENT SYNTHESIS OF $\beta$-AMINO KETONES VIA MANNICH REACTION APPROACH USING HETEROGENEOUS SNPS CATALYSTS
}

\author{
Jagannath Jadhav' ${ }^{1}$, Kanchan S. Joshi-Kulkarni' ${ }^{2, *}$ and B. D. Ajalkar ${ }^{3}$ \\ ${ }^{1}$ Department of Chemistry, Shivaji University, Kolhapur-416004, (Maharashtra) India \\ ${ }^{2}$ Department of Chemistry, Jagruti Jr. College, Gadhinglaj-416502, (Maharashtra) India \\ ${ }^{3}$ Department of Chemistry, Shivraj College, Gadhinglaj-416502, (Maharashtra) India \\ *E-mail: devalpallykanchan@gmail.com
}

\begin{abstract}
A highly efficient novel method for the synthesis of $\beta$-amino ketones via a one-pot three-component Mannich reaction in the presence of silica nanoparticles (SNPs) under microwave (MW) irradiation is described. The formation of both $\mathrm{C}-\mathrm{C}$ and $\mathrm{C}-\mathrm{N}$ bonds occurs through a multicomponent reaction (MCR) of an enolizable carbonyl compound with an imine intermediate generated from the condensation of amine and aldehyde, yielded the title compound, which was structurally characterized, in high yields. The noteworthy features of the present protocol include simple substrate material, low catalyst loading, remarkable catalytic performance, solvent-free reaction conditions, clean reaction profile, shorter reaction time, recyclability of catalyst, an excellent yield of $\beta$-amino carbonyl compounds without any by-products.
\end{abstract}

Keywords: Mannich Reaction, Microwave, Multi-component Reaction (MCR), Pharmaceuticals, Silica Nanoparticles (SNPs).

() RASĀYAN. All rights reserved

\section{INTRODUCTION}

Although silica is generally non-cytotoxic, designing of silica into nanomaterial change its physicochemical properties and thus can be used in biomedical devices as well as inefficient drug delivery systems. SNPs have been studied widely due to their mesoporous structure and favorable surface chemistry. SNPs are of great scientific interest as these are in effect, a bridge between bulk material and atomic or molecular structures. SNPs have unique properties like chemical and thermal stability, more porosity, biocompatibility and multi-functionality. ${ }^{1}$ Moreover they have some special properties like the site-specific target of drugs biomedical domain, excellent functional properties, high versatility, low toxic and low-cost production. Indeed SNPs have shown the tremendous potential of absorbents and carriers of drugs. ${ }^{2}$ Thus, SNPs is the growing interest of therapeutic and target specific drug. ${ }^{3}$

The important attribute of the silica nanoparticle is its effortless preparation by classical Stober method ${ }^{4}$ as well as a functional modification as they have reactive hydroxyl groups at the surface. On the other hand due to its Lewis-Bronsted acidic nature, ${ }^{5}$ they have been employed as heterogeneous catalysts. It has spurred extensive interest in applications as a heterogeneous catalyst in many of the reactions like MizorokiHeck reaction, Beginelli reaction and Mannich reaction. The most significant reports involved in catalytic application SNPs cover carbon-carbon as well as carbon-nitrogen bond-forming reactions. To our delight, the Mannich type reactions were scarcely studied by using SNPs. ${ }^{6}$ There were only a few records available in the literature and most of them suffer from several drawbacks. So to overcome these drawbacks associated with previous techniques, we have chosen here to use SNPs as an efficient catalyst. Mannich reaction, ${ }^{7-8}$ offers a robust method for the preparation of the $\beta$-aminocarbonyl and several other derivatives. ${ }^{9-17}$ Further, in several instances, $\beta$-amino carbonyl products are valuable synthons for natural product synthesis. ${ }^{18} \beta$-amino carbonyl compounds are frequently useful as synthetic building blocks ${ }^{19-23}$ and their derivatives, which exhibits better activity than the corresponding parent drug analogs. (Fig.-1) ${ }^{24}$

Rasayan J. Chem., 13(3), 1842-1852(2020)

http://dx.doi.org/10.31788/ RJC.2020.1335758

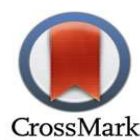


RASĀYAN J. Chem.

Vol. 13 | No. 3 |1842-1852| July - September | 2020

Therefore, Mannich reaction has been witnessing continuous growth in the field of organic chemistry and the resultant $\beta$-amino carbonyl compounds bring forth diverse structural features by displaying a wide range of potent biological activities in medicinal chemistry. ${ }^{25-34}$

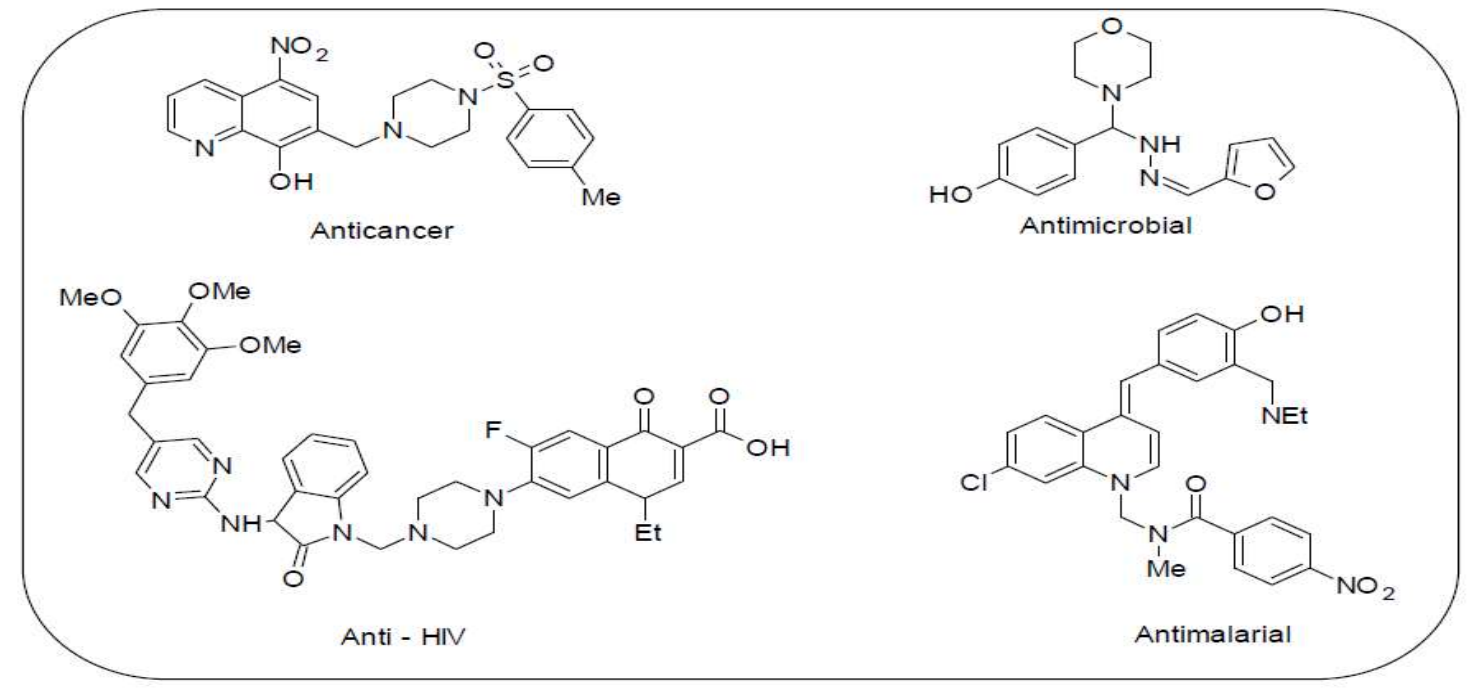

Fig.-1: Examples of Bio-active Mannich Bases

The survey of literature on Mannich reaction provides several synthetic methods using inorganic acid and organic catalysts for the preparation of $\beta$-amino carbonyl compound. ${ }^{35-41}$ However, most of the reported methods suffer from drawbacks such as poor yields, long reaction times, harsh reaction conditions, toxicity and difficulty in product separation, which limits in the synthesis of this $\beta$-amino carbonyl architecture. Therefore there is a need to develop an efficient method using environmentally benign heterogeneous SNPs catalyzed synthesis of $\beta$-amino carbonyl compounds. Thus in continuation of our work related to green chemistry we wish to report here the use of SNPs as catalyst under microwave for the one-pot multicomponent synthesis of $\beta$-amino carbonyl compounds via Mannich reaction approach of diverse acetyl ketones, aromatic aldehydes and aromatic amines with the hope of obtaining compounds will help in the building of medicinally active scaffold and possess diverse biological activities (Depicted Graphically Below).

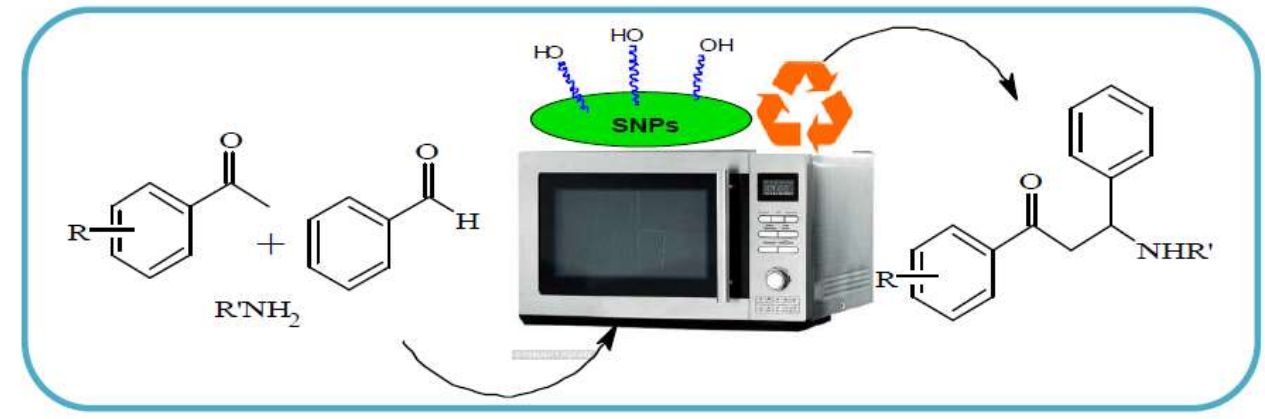

\section{EXPERIMENTAL}

All solvents and reagents were obtained from commercial sources and were dried and purified when necessary by standard techniques. The SNPs obtained from Sigma-Aldrich. The synthesis of $\beta$-amino carbonyl compound was conducted in Microwave oven - ONIDA POWER SOLO 20 (240W, $2450 \mathrm{MHz})$ as per general procedure without any modification. All reactions were monitored by thin-layer chromatography (TLC) using pre-coated aluminium sheet silica gel (Merck $60 \mathrm{~F} 254$ ) and visualized by ultraviolet (UV) lamp of wavelength $\lambda=254 \mathrm{~nm}$. All compounds reported here were purified on column chromatography with a mobile phase which is a mixture of hexane and ethyl acetate in proportion $(\mathrm{v} / \mathrm{v}, 6 / 4)$ and phase stationary silica (Silica gel 60-120 $\mu \mathrm{m}$ ). Melting point of each product was determined in an open 
capillary apparatus and is uncorrected. The characterization of all synthesized compounds was made using several instrumental techniques. The IR spectra were recorded on Shimadzu FT-IR 157 spectrophotometry $(\mathrm{KBr} \operatorname{discs} \sim 5 \% \mathrm{w} / \mathrm{w}), 1 \mathrm{H}$ and $13 \mathrm{C}$ NMR spectra were recorded on a Brucker spectrometer at $300 \mathrm{MHz}$ and $75 \mathrm{MHz}$, respectively using $\mathrm{CDCl} 3$ as solvent and tetramethylsilane (TMS, $\delta=0 \mathrm{ppm}$ ) as an internal standard. Chemical shifts of protons were reported in parts per million (ppm) downfield from TMS. Coupling constants are reported in Hertz (Hz). The C.H.N elemental analysis was performed on the EURO EA3000 vector model.

\section{General Procedure for the Synthesis of $\beta$-Amino Carbonyl Compounds}

A mixture of aromatic amine $(1 \mathrm{mmol})$, aromatic aldehyde $(1.1 \mathrm{mmol})$, acetophenone $(1.1 \mathrm{mmol})$, and catalyst SNPs $(0.1 \mathrm{gm})$ was irradiated in a microwave oven $(240 \mathrm{~W})$ for the appropriate time as indicated in Table-3 and progress of the reaction was monitored by TLC. After completion, the reaction mixture was diluted with ethyl acetate $(5 \mathrm{~mL})$ and filtered to separate the catalyst. The SNPs catalyst obtained was washed with ethyl acetate $(5 \mathrm{~mL})$, dried and stored for reuse. The filtered product was dried over anhydrous sodium sulfate and the residue was subjected to column chromatography (silica gel, hexane-EtOAc; v/v, $6 / 4$ ) to obtain pure $\beta$-amino carbonyl compounds.

The characterization of products is made by using FT-IR, 13CNMR, 1HNMR, mass spectra, etc. The melting points of the compounds were recorded by open capillary apparatus and were uncorrected.

\section{Spectral Data of Representative Compounds}

1, 3-Diphenyl-3-(phenyl amino) propan-1-one (Table-3, entry 1)

Colorless solid; MP 170-172 ${ }^{\circ} \mathrm{C} .7 \mathrm{IR}$ (KBr, thin film): $v=3120,3053,2964,2920,2855,1698,1536,1464$, 1438, 1111, 1071, 998, 799, $766 \mathrm{~cm}-1,1 \mathrm{H}$ NMR (300 MHz, CDCl3): $\delta 7.90$ (d, 2H, Ar-H), $7.56(\mathrm{~m}, 1 \mathrm{H}$, Ar-H), 7.45-7.29 (m, 4H, Ar-H), 7.28-7.17 (m, 4H, Ar-H), 7.14-7.12 (m, 2H, Ar-H), 6.85-6.25 (m, 3H, ArH), 5.06 (t, 1H, -CH), 3.70 (d,2H, CH2).13C NMR (75 MHz, CDCl3): $\delta 198.2(\mathrm{C}=\mathrm{O})$ 146.2, 142.7, 136.7, 133.4, 129.1, 128.3, 128.2, 127.4, 122.1, 118.0, 114.0 (Ar-C), 77.4, 76.6, 55.0 (C-O) 46.2 (aliphatic C-C), Elemental Analysis requires: C 82.59, H 6.44, N 4.73\%. C21H19NO: found: C 83.69, H 6.35, N 4.65\%. MS (EI): $\mathrm{m} / \mathrm{z}=302.15(\mathrm{M}+)$.

\section{3-(4-Chlorophenyl)-1-phenyl-3-(phenyl amino) propan-1-one (Table-3, entry 3)}

Colorless solid; MP 113-115 ${ }^{\circ} \mathrm{C} .21 \mathrm{IR}(\mathrm{KBr}$, thin film):v = 3391, 3016, 2398, 1685, 1603, 1507, 1442, 1404, 1217, 1018, 821, 752, $698 \mathrm{~cm}-1$. 1H NMR (300 MHz, CDCl3): $\delta$ 7.96-7.90 (m, 2H, Ar-H), 7.68-7.29 $(\mathrm{m}, 7 \mathrm{H}, \mathrm{Ar}-\mathrm{H}), 7.19(\mathrm{t}, \mathrm{J}=7.8 \mathrm{~Hz}, 2 \mathrm{H}, \mathrm{Ar}-\mathrm{H}), 6.72(\mathrm{t}, \mathrm{J}=7.3 \mathrm{~Hz}, 1 \mathrm{H}, \mathrm{Ar}-\mathrm{H}), 6.71(\mathrm{~d}, \mathrm{~J}=7.9 \mathrm{~Hz}, 2 \mathrm{H}, \mathrm{Ar}-$ $\mathrm{H}), 5.02(\mathrm{t}, \mathrm{J}=6.8 \mathrm{~Hz}, 1 \mathrm{H},-\mathrm{CH}), 3.51(\mathrm{~d}, \mathrm{~J}=6.4 \mathrm{~Hz}, 2 \mathrm{H},-\mathrm{CH} 2) .13 \mathrm{C} \mathrm{NMR}(75 \mathrm{MHz}, \mathrm{CDCl}): \delta$ 197.2, 146.9, 141.1, 136.2, 133.1, 135.0, 128.6, 128.2, 128.1, 121.1, 128.1, 118.9, 114.7, 54.8, 47.0. Elemental Analysis requires: C 75.15\%, H 5.45\%, N 4.23\%. C21H18NOCl: found: C 75.11\%, H 5.40\%, N 4.17\%. MS (EI): $\mathrm{m} / \mathrm{z}=336.11(\mathrm{M}+)$.

\section{3-(4-Bromophenylamino)-1,3-diphenylpropan-1-one (Table-3, entry 4)}

Colorless solid; MP 126- $127{ }^{\circ} \mathrm{C} .21 \mathrm{IR}$ (KBr, thin film): $v=3371,3022,1668,1599,1581,1502,1441$, 1401, 1315, 1289, 1078, 914, $841 \mathrm{~cm}-1$. 1H NMR (300 MHz, CDCl3): $7.95-7.87$ (d, J = 7.5 Hz, 2H, Ar$\mathrm{H}), 7.65-7.55(\mathrm{t}, 1 \mathrm{H}), 7.52-7.42(\mathrm{t}, 4 \mathrm{H}), 7.40-7.30(\mathrm{~d}, 2 \mathrm{H}), 7.15-7.07(\mathrm{t}, 2 \mathrm{H}), 6.75-6.65(\mathrm{t}, 1 \mathrm{H}), 6.60-6.50$ (d, 2H), 5.05-4.90(t, 1H), 3.61 (d, J = 6.2 Hz, 2H, -CH2). 13C NMR (75 MHz, CDCl3): $\delta 198.09,146.86$, $142.27,136.70,133.85,132.14,129.39,129.00,128.43,128.41,121.26,118.30,114.06,54.42,46.30$. Elemental Analysis requires: C 66.35\%, H 4.45\%, N 3.70\%. C21H18NOBr: found: C 66.33\%, H 4.77\%, $\mathrm{N} 3.68 \%$. MS (EI): $\mathrm{m} / \mathrm{z}=381.0(\mathrm{M}+)$.

\section{1-(4-aminophenyl)-3-phenyl-3-(phenyl amino) propan-1-one (Table-3, entry 8)}

Yellow solid; MP $107-108^{\circ} \mathrm{C}$. IR (KBr, thin film): $v=3385,3325,3220,2924,1639,1552,1578,1225$, 1174, 985, 835, $766 \mathrm{~cm}-1.1 \mathrm{H}$ NMR (300 MHz, CDCl3): $\delta$ 7.95-7.93 (m, 1H, Ar-H), 7.83-7.65 (m, 4H, ArH), 7.63-7.05 (m, 5H, Ar-H), 6.71-6.51 (m, 5H, Ar-H), 4.98-4.90 (m, 1H, -CH), 4.21-4.16 (bs, 2H, NH2), 3.41-3.24 (m, 2H, -CH2). 13C NMR (75 MHz, CDCl3): $\delta 196.5,188.1,151.4,151.1,147.2,143.4,135.3$, 
RASĀYAN J. Chem.

Vol. 13 | No. 3 |1842-1852| July - September | 2020

131.4, 130.8, 130.0, 129.0, 128.8, 128.2, 127.8, 127.1, 126.3, 122.0, 117.1, 113.9, 113.7, 55.2, 45.7, Elemental Analysis requires: C 79.59\%, H 6.42\%, N 8.78\%. C21H20N2O: found: C 79.72\%, H 6.37\%, N 8.85\%. MS (EI): $\mathrm{m} / \mathrm{z}=317.1(\mathrm{M}+)$.

\section{RESULTS AND DISCUSSION}

Our initial studies were directed towards the optimization of reaction conditions where SNPs will act as a Lewis acid catalyst and going to provide better results in acquiring $\beta$-amino carbonyl compound. Compared to that of the conventional method, the use of microwave irradiation is more advantageous and offers significant product formation within a short period. To prove our hypothesis, initially, we chose a one-pot three-component reaction of benzaldehydes, aniline and acetophenone as model substrates for the optimization of reaction parameters. The optimization of catalyst quantity was studied on model substrates by taking SNPs from $0.0 \mathrm{~g}$ to $0.120 \mathrm{~g}$ by choosing ethanol as a solvent (Table-1, entries 1 to 9 ). As shown in Table 1 the yield of $\beta$-amino carbonyl compounds was increased with an increase in catalyst SNPs from 0.0 to $0.1 \mathrm{gm}$ (Table-1, entries 1-6). However further increase in temperature as well as the amount of catalyst doesn't show any considerable increase in product yield (Table1, entries 6-9). The efforts on optimization of temperature for reaction proved to be a crucial factor. When the model reaction performed at $80^{\circ} \mathrm{C}$ with $0.1 \mathrm{gm}$ of catalyst gave the superior result as compared with higher temperature reaction conditions (Table-1, entries 7-9). Also, there was no further improvement in the yield of the product when the increase in catalyst loading. (Table-1, entries 8-9). Thus, $0.1 \mathrm{gm}$ of SNPs and $80^{\circ} \mathrm{C}$ operational temperatures in ethanol was considered the best compromise and were extended to the further optimization in solvent studies.

Table-1: Effect of Amount of SNPs on Model Reaction ${ }^{\mathrm{a}}$<smiles>CC(=O)c1ccccc1</smiles>

\begin{tabular}{ccccc}
\hline Entry & Catalyst $(\mathbf{g})$ & Temp $\left({ }^{\circ} \mathbf{C}\right)$ & Time $($ min) & ${ }^{b}$ Yields (\%) \\
\hline 1 & 0.000 & 80 & 60 & None \\
2 & 0.020 & 80 & 50 & 56 \\
3 & 0.040 & 80 & 30 & 69 \\
4 & 0.060 & 80 & 15 & 76 \\
5 & 0.080 & 80 & 10 & 83 \\
6 & 0.100 & 80 & 05 & 90 \\
7 & 0.100 & 100 & 05 & 91 \\
8 & 0.120 & 80 & 05 & 91 \\
9 & 0.120 & 100 & 05 & 92
\end{tabular}

${ }^{a}$ Reaction conditions: Acetophenone $(1.1 \mathrm{mmol})$, Benzaldehyde $(1.1 \mathrm{mmol})$, Aniline $(1 \mathrm{mmol})$, SNPs $(0.100 \mathrm{gm})$, $\mathrm{MW}, 80 \mathrm{C}, 5 \mathrm{~min}$. ${ }^{\mathrm{b}}$ Isolated yields after chromatography.

With the optimum catalyst loading condition in our hand, we moved onward to determine the effect of stoichiometric ratio of catalytic loading on both percentage conversion and purity of the crude product. Accordingly, to investigate the effect of the amount of SNPs catalyst on the rate and yield of product, the model reaction was screened by varying the solvent at a variable temperature as well as the solvent-free condition and the results are summarized in Table 2. As seen in Table-2, the use of ethanol was effective in providing higher conversion (Table-2, entry 4) whereas in chlorinated solvents like $\mathrm{CH} 2 \mathrm{Cl} 2, \mathrm{CHCl} 3$ (Table 2, entries 1-2), in protic solvents like $\mathrm{H} 2 \mathrm{O}, \mathrm{MeOH}$ (Table-2, entries 3, 5) and aprotic solvents like CH3CN, THF, DMF, Toluene etc. (Table-2, entries 6-9) showing lower conversions for formation desired 
RASĀYAN J. Chem.

Vol. 13 | No. 3 |1842-1852 | July - September | 2020

product. Surprisingly the effort on solvent-free condition reaction conditions furnishes excellent product formation. (Table-2, entry 10) Thus witnessed from this encouraging outcome, we put an extra effort towards solvent-free reaction conditions.

By optimizing the reaction conditions, we scrutinized the generality of the protocol by reacting structurally diverse aldehyde, amines as well as substituted acetophenone bearing electron-donating and electronwithdrawing groups, the results were summarized in Table 3 . An interesting feature of the reaction is the high reactivity of substrates bearing halide substituent's thus providing an opportunity for additional synthetic manipulation (Table-3, entries $3,4,10,14$ ). The characterizations of the products were determined by IR, 1H NMR and 13C NMR spectroscopy as well as by mass spectrometry and the values are in good harmony with literature data.

Table-2: Effect of Solvent on Model Reaction<smiles>CC(=O)c1ccccc1</smiles>

(1a)<smiles>O=Cc1ccccc1</smiles>

(2a)

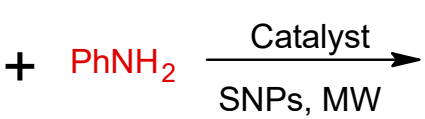

(3a)<smiles>O=C(CC(Nc1ccccc1)c1ccccc1)c1ccccc1</smiles>

(4a)

\begin{tabular}{ccc}
\hline Entry & Solvents & \% Yield \\
\hline 1 & $\mathrm{CHCl}_{3}$ & 57 \\
2 & $\mathrm{CH}_{2} \mathrm{Cl}_{2}$ & 62 \\
3 & $\mathrm{MeOH}$ & 72 \\
4 & $\mathrm{EtOH}$ & 80 \\
5 & $\mathrm{H}_{2} \mathrm{O}$ & Trace \\
6 & $\mathrm{CH}_{3} \mathrm{CN}$ & 70 \\
7 & $\mathrm{THF}$ & 48 \\
8 & $\mathrm{DMF}$ & 51 \\
9 & Toluene & 67 \\
10 & Solvent free & 92 \\
\hline
\end{tabular}

aReaction conditions: Acetophenone $(1.1 \mathrm{mmol})$, Benzaldehyde $(1.1 \mathrm{mmol})$, Aniline $(1 \mathrm{mmol})$, Solvent $(5 \mathrm{ml})$ or solvent-free, SNPs (0.100 gm), MW, $80 \mathrm{C}, 5 \mathrm{~min}$. ' Isolated yields after chromatography.

\section{Mechanism}

The formation of both carbon-carbon and carbon-nitrogen bonds via multi-component reaction (MCR) condenses an amine, an enolizable carbonyl compound (donor) and a non-enolizable carbonyl compound (acceptor) which yielded a $\beta$-amino carbonyl compound (ketone or ester), it is an example of Mannich Reaction. Therefore based on literature ${ }^{48}$ and considering Lewis-Brønsted acidic nature of SNPs, the plausible mechanism catalyzed by SNPs is shown in Fig.-2. Initially, the catalyst coordinates with the carbonyl oxygen of the aldehyde, helping the nucleophilic attack of aniline leading to the formation of imine by liberation of a water molecule. This imine further reacts with activated enolate, followed by proton transfer led the desired $\beta$-amino carbonyl compound with the regeneration of SNPs.

\section{Catalyst Re-usability Study}

The successful recovery and reuse of catalysts from the reaction mixture is an extremely essential aspect from an economic and environmental point of view. Hence we focused our attention on the recyclability and reusability of SNPs to reinforce the advantage of catalysts. For this study, we chose the same model reaction of acetophenone, benzaldehyde and aniline, under optimized conditions. By the completion of the reaction, the catalyst was filtered, washed with a copious amount of ethyl acetate to remove any adhered 
RASĀYAN J. Chem.

Vol. 13 | No. 3 |1842-1852 | July - September | 2020

reactant and dried at $60^{\circ} \mathrm{C}$ in a vacuum for $1 \mathrm{~h}$. This recovered and reactivated catalyst was reused in subsequent runs. We prominently note that the SNPs could be reused for four runs on model reaction without a noticeable drop in the product yield and catalytic activity (Fig.-3). Also, it was noticed that the catalytic activity of SNPs did not change even after one week of air exposure at room temperature.

Table-3: Synthesis of $\beta$-Amino Carbonyl Compounds by Using SNPs ${ }^{\mathrm{a}}$<smiles>[R]c1ccccc1C=O</smiles>

(1)<smiles>O=Cc1ccccc1</smiles>

(2)<smiles>[3H]N</smiles>

(3)<smiles>[R]NC(CC(=O)c1ccccc1)c1ccccc1</smiles>

(4)

\begin{tabular}{|c|c|c|c|c|c|c|c|}
\hline Entry & $\begin{array}{l}\mathrm{R} \\
(1) \\
\end{array}$ & $\begin{array}{l}\mathrm{Ar} \\
(2)\end{array}$ & $\begin{array}{l}\text { R' } \\
\text { (3) }\end{array}$ & $\begin{array}{c}\text { Product } \\
\text { (4) }\end{array}$ & $\begin{array}{l}\text { Time } \\
(\min )\end{array}$ & $\begin{array}{c}{ }^{\text {byield }} \\
(\%)\end{array}$ & M.P $\left({ }^{\circ} \mathrm{C}\right)$ \\
\hline 1 & $\mathrm{H}$ & $\mathrm{Ph}$ & $\mathrm{Ph}$ & & & 90 & $\begin{array}{l}170- \\
172^{13}\end{array}$ \\
\hline 2 & $\mathrm{H}$ & $\begin{array}{c}4- \\
\mathrm{OMePh}\end{array}$ & $\mathrm{Ph}$ & & 7.5 & 77 & $\begin{array}{l}144- \\
145^{45}\end{array}$ \\
\hline 3 & $\mathrm{H}$ & 4-ClPh & $\mathrm{Ph}$ & & 4 & 94 & $\begin{array}{l}113- \\
115^{44}\end{array}$ \\
\hline 4 & $\mathrm{H}$ & 4-BrPh & $\mathrm{Ph}$ & & 5 & 93 & $\begin{array}{l}126- \\
127^{44}\end{array}$ \\
\hline 5 & $\mathrm{H}$ & $3-\mathrm{NO}_{2} \mathrm{Ph}$ & $\mathrm{Ph}$ & & 8 & 72 & $\begin{array}{l}130- \\
132^{13}\end{array}$ \\
\hline 6 & $\mathrm{H}$ & $4-\mathrm{NO}_{2} \mathrm{Ph}$ & $\mathrm{Ph}$ & & 9.5 & 69 & $\begin{array}{l}110- \\
111^{46}\end{array}$ \\
\hline 7 & $\mathrm{H}$ & $\begin{array}{c}2,5- \\
\text { diOMeP } \\
\text { h }\end{array}$ & $\mathrm{Ph}$ & & 8 & 75 & $\begin{array}{l}175- \\
176^{44}\end{array}$ \\
\hline 8 & 4- $\mathrm{NH}_{2}$ & $\mathrm{Ph}$ & $\mathrm{Ph}$ & & 9 & 70 & $107-108$ \\
\hline & & & & & & & \\
\hline
\end{tabular}


RASĀYAN J. Chem.

Vol. 13 | No. 3 |1842-1852 | July - September | 2020

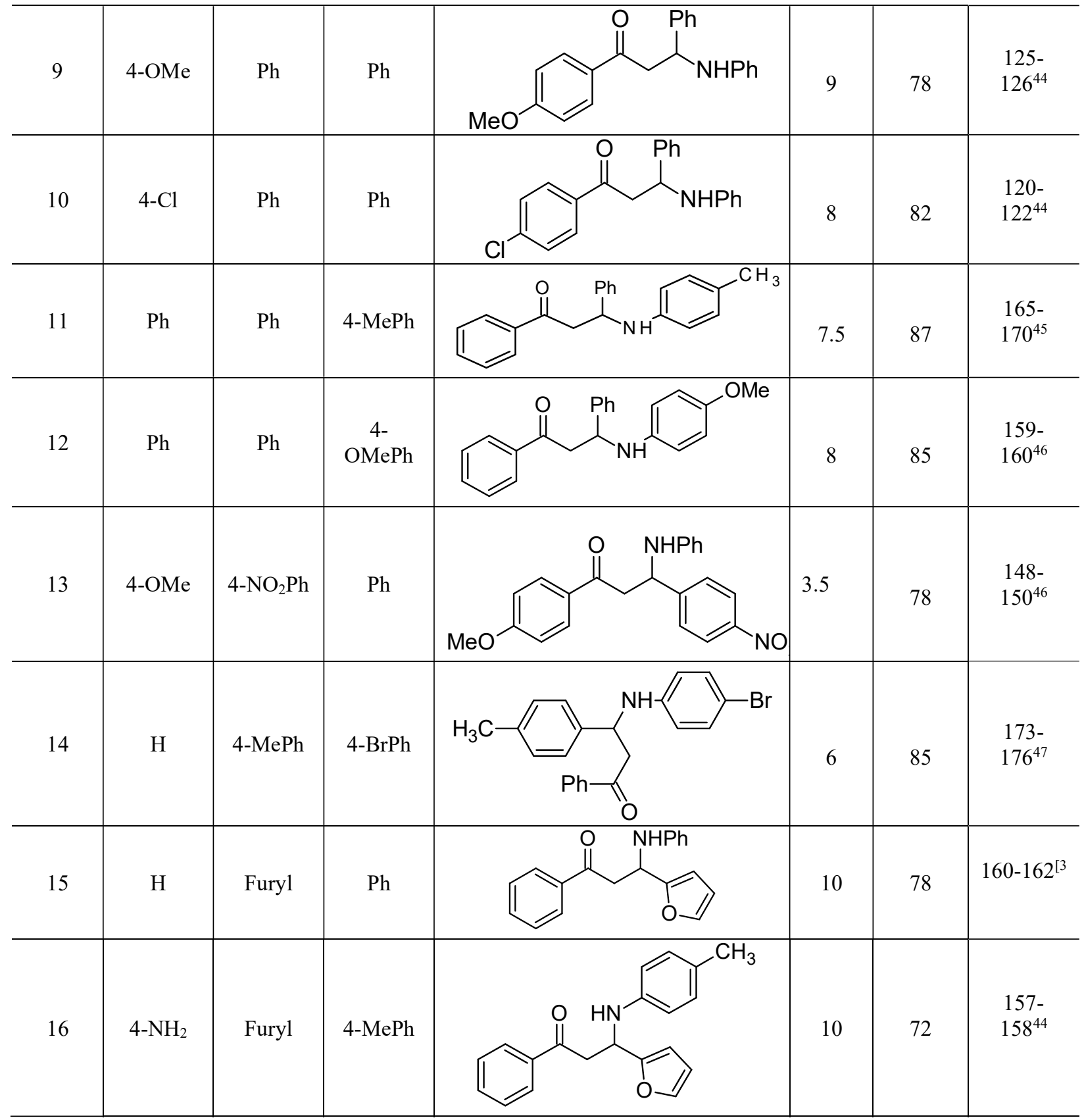

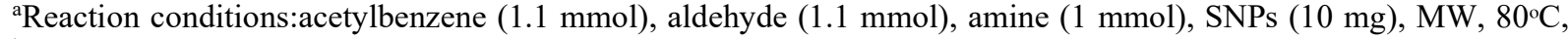
b Isolated yields after chromatography

\section{Comparative Study of SNPs}

As we summarized the result in Table-4, it was clear that SNPs is excellent and superior to many other reported catalysts (Table-4, entry 1-6) concerning the amount of loading of catalyst, temperature, time, the yield of product, recyclability and reusability of catalyst. Thus, it was concluded that the utilized SNPs not only an efficient catalyst to increases the yield of the product but also accelerates the reaction rate than the reported one. 
RASĀYAN J. Chem.

Vol. 13 | No. 3 |1842-1852| July - September | 2020

regeneration of SNP

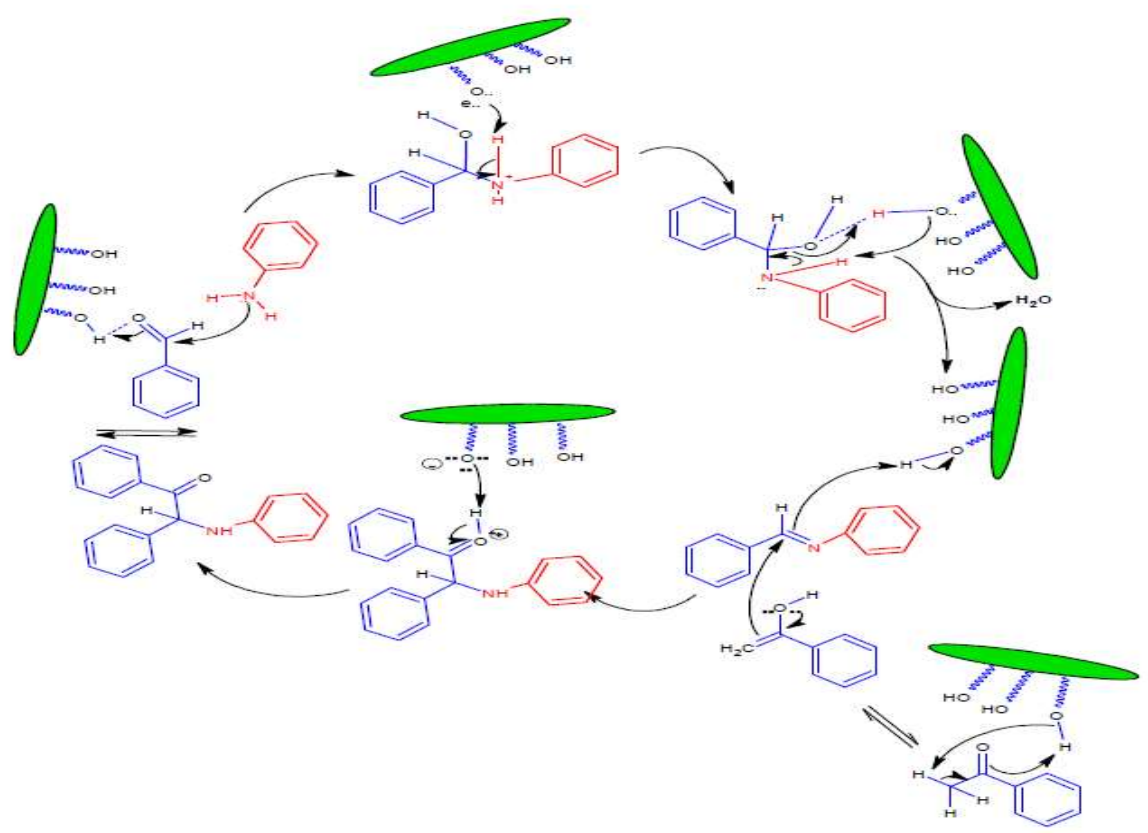

Fig.-2: Plausible Mechanism Catalyzed by SNPs

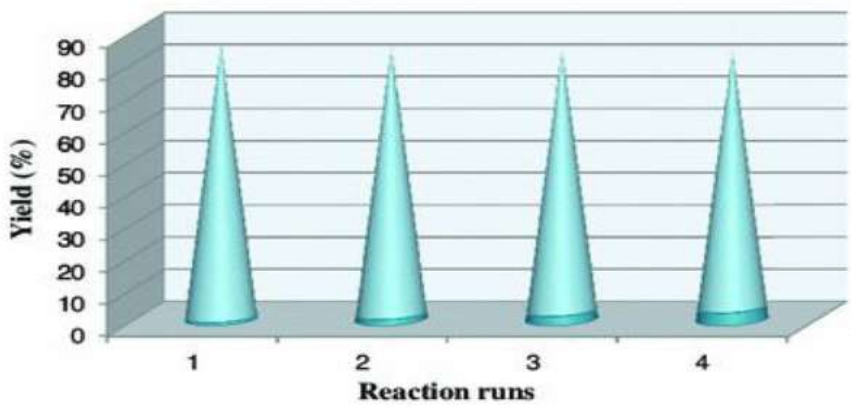

Fig.-3: Recyclability Study of SNPs

Table-4: Comparative Studies of SNPs against Reported Catalyst towards the Synthesis of 1, 3-Diphenyl-3-(phenyl amino) propan-1-one

\begin{tabular}{|c|c|c|c|c|c|c|}
\hline Entry & Catalyst / Solvent & $\begin{array}{c}\text { Amount of } \\
\text { catalyst }\end{array}$ & $\begin{array}{l}\text { Temp } \\
\left({ }^{\circ} \mathrm{C}\right)\end{array}$ & Time (h) & $\begin{array}{l}\text { Yield } \\
(\%)\end{array}$ & Ref. \\
\hline 1 & $\mathrm{SiO}_{2}-\mathrm{OAlCl}_{2} / \mathrm{EtOH}$ & $0.05 \mathrm{~g}$ & rt & 5 & 93 & {$[13]$} \\
\hline 2 & $\mathrm{FeCl}_{3}$ : Silica gel G/EtOH & $1: 1$ & $\mathrm{rt}$ & 5 & 94 & {$[16]$} \\
\hline 3 & $\begin{array}{c}\text { Carbon based solid acid (CBSA) / } \\
\text { EtOH }\end{array}$ & $0.10 \mathrm{~g}$. & $\mathrm{rt}$ & $3: 45$ & 90 & {$[48]$} \\
\hline 4 & $\begin{array}{c}\text { Sultone-based ionic liquids-PS- } \\
\text { PTSA }\end{array}$ & $0.65 \mathrm{~g}$ & $\mathrm{rt}$ & 2 & 87 & [49] \\
\hline 5 & Nano-SZ / EtOH & $10 \mathrm{~mol} \%$ & $\mathrm{rt}$ & 5 & 90 & {$[50]$} \\
\hline 6 & Mesoporous NSPs/EtOH & $0.1 \mathrm{~g}$ & $\mathrm{rt}$ & 3.25 & 87 & {$[51]$} \\
\hline 7 & NSPs/MW & $0.1 \mathrm{~g}$. & 80 & $5 \mathrm{~min}$ & 90 & $\begin{array}{c}\text { Present } \\
\text { work }\end{array}$ \\
\hline
\end{tabular}


RASĀYAN J. Chem.

Vol. 13 | No. 3 |1842-1852| July - September | 2020

\section{CONCLUSION}

It has been found that SNPs acts as an efficient catalyst in the synthesis of $\beta$-amino carbonyl compounds (Mannich base) via a one-pot three-component reaction (MCR). Thus present strategy offers several advantages including low catalyst loading, remarkable catalytic performance, avoided harmful organic solvents as the reaction is solvent-free, clean reaction profile, shorter reaction time, green synthesis, recyclability and reusability of catalyst, an excellent yield of $\beta$-amino carbonyl compounds without any byproducts by maintaining environmentally greener protocol. Therefore, we believe that this pollution-free, with greater atom economy, excellent synthetic methodology with low cost, an alternative method for further studies in Mannich reactions.

\section{REFERENCES}

1. D. Ma, Cao Zhanyi and A. Hu. Nano-Micro Letters, 6, 347(2014), DOI:10.1007/s40820-0140008-2.

2. M. Benezra, O. Medina-Penate, P. B. Zanzonico, D. Schaer, H. Ow, A. Burns, E. DeStanchina, V. Longo, E. Herz, S. Iyer, J. Wolchok, S. M. Larson, U. Wiesner and M. S. Bradbury, Journal of Clinical Investigation, 121, 2768(2011), DOI:10.1172/JCI45600.

3. M. Edrissi, M. Soleymani and M. Adinehnia, Chemical Engineering \& Technology, 34, 1813(2011), DOI: $10.1002 /$ ceat.201100195.

4. W. Stöber, A. Fink and E. Bohn, Journal of Colloid And Interface Science, 26(1), 62(1968), DOI:10.1016/0021-9797(68)90272-5.

5. R. K. Kankala, P. -Y. Tsai, Y. Kuthati, P. -R. Wei, C. -L. Liu and C. -H. Lee, Journal of Materials Chemistry, B, 5, 1507(2017), DOI:10.1039/C6TB03146C.

6. (a) S. Iimura, D. Nobutou, K. Manabe and S. Kobayashi, Chemical Communications, 1644(2003), DOI:10.1039/B304343F; (b) H. Wu, Y. Shen, L-y Fan, Y. Wan, P. Zhang, C. -f. Chen and W. -X, Wang, Tetrahedron, 63, 2404(2007), DOI:10.1016/j.tet.2007.01.015; (c)D. Zareyee and H. Alizadeh, RSC-Advances, 4, 37941(2014), DOI:10.1039/C4RA05842A.

7. (a) N. Azizi, L. Torkiyan and M. R. Saidi, Organic Letters, 8, 2079(2006), DOI:10.1021/o1060498v; (b) E. Rafiee, S. Eavani, F. K. Nejad and M. Joshaghani, Tetrahedron, 66, 6858(2010), DOI:10.1016/j.tet.2010.06.052; (c)M. A. Bigdeli, F. Nemati and G. H. Mahdavinia, Tetrahedron Letters, 48, 6801(2007), DOI:10.1016/j.tetlet.2007.07.088; (d)Z. Li, X. Ma, J. Liu, X. Feng, G. Tian and A. Zhu, Journal of Molecular Catalysis A: Chemical, 272, 132(2007), DOI:10.1016/j.molcata.2007.03.029, (e)W. -Y. Li, Y. -X, Zong, J. -K. Wang and Y. -Y, Niu, Chinese Chemical Letters, 25, 575(2014), DOI:10.1016/j.cclet.2013.11.022, (f)R. K. Sharma, D. Rawat and G. Gaba, Catalysis Communications,19, 31(2012), DOI:10.1016/j.catcom.2011.12.006.

8. (a) S. Iimura, D. Nobutou, K. Manabe and S. Kobayashi, Chemical Communications, 1644(2003), DOI:10.1039/B304343F, (b)H. Wu, Y. Shen, L-y. Fan, Y. Wan, P. Zhang, C-f. Chen and W-x. Wang, Tetrahedron, 63, 2404(2007), DOI:10.1016/j.tet.2007.01.015, (c)D. Zareyee and H. Alizadeh, RSC Advances, 4, 37941(2014), DOI:10.1039/C4RA05842A.

9. M. Xue-Lin, Z. Xiao-Yong and Y. Sheng-Li, Chemical Journal of Chinese Universities, 34, 2759(2013)

10. V. Kumar, U. Sharma, P. K. Verma, N. Kumar and B. Singh, Chemical and Pharmaceutical Bulletin, 59, 639(2011), DOI:10.1248/cpb.59.639.

11. Z. Li, X. Ma, J. Liu, X. Feng, G. Tian and A. Zhu, Journal of Molecular Catalysis A: Chemical, 272, 132(2007), DOI:10.1016/j.molcata.2007.03.029.

12. Z. Nasresfahani, M. Z. Kassaee, M. N. Shendi, E. Eidia and Q. Taheri, RSC-Advances, 6, 32183(2016), DOI: 10.1039/C6RA02454H.

13. D. Sachdev, A. Dubey, G. R. Wilson and A. Sharma, New Journal of Chemistry, 39, 2633(2015), DOI: $10.1039 /$ C4NJ01748J.

14. R. Singh, G. Bhasin, S. Geetanjali and R. Srivastava, Journal of Chemical and Pharmaceutical Research, 6, 776(2014).

15. (a) R. S. Varma, Green Chemistry, 1, 43(1999), DOI:10.1039/A808223E, (b)E. Gershonov, E. Katz, Y. Karton and Y. Zafrani, Tetrahedron, 63, 3762(2007), DOI:10.1016/j.tet.2007.02.061. 
16. (a) R. S. Varma and R. K. Sanini, Tetrahedron Letters, 38, 4337(1997), DOI:10.1016/S00404039(97)00968-4; (b)C. E. Song and S. G. Lee, Chemical Reviews, 102, 3495(2002), DOI: $10.1021 / \mathrm{cr} 0103625$.

17. D. Bahulayan, G. Narayan, V. Sreekumar and M. Lalithambika, Synthetic Communications, 32, 3565(2002), DOI:10.1081/SCC-120014967.

18. (a) E. J. Corey and R. D .Balanson, Journal of American Chemical Society, 96, 6516(1974), DOI:10.1021/ja00827a046; (b)S. Knight, L. E. Overman and G. J. Pairaudeau, Journal of American Chemical Society, 115, 9293(1993), DOI:10.1021/ja00073a057.

19. T. Plech, M. Wujec, M. Majewska, U. Kosikowska and A. Malm, Medicinal Chemistry Research, 22, 2531(2013), DOI: 10.1007/s00044-012-0248-y.

20. P. Jadhav, R. R. Pujari and N. R. Chatterjee, International Journal of Biomedical Research, 3, 334(2012)

21. N. G. Li, S. L. Song, M. Z. Shen, Y. P. Tang, Z. H. Shi, H. Tang and J. A. Duan, Bioorganic Medicinal Chemistry, 20, 6919(2012), DOI:10.1016/j.bmc.2012.10.015.

22. V. Khanna, S. R. Parashar, P. H. Ladwa and M. B. Bhinde, Indian Journal of Chemistry, 25, 102, (1986).

23. M. I. Hussain and U. P. Shrivastava, Indian Journal of Pharmaceutical Science, 46, 103(1984)

24. (a) S. Bala, N. Sharma, A. Kajal, S. Kamboj and V. Saini, International Journal of Medicinal Chemistry, 191072(2014), DOI:10.1155/ 2014/191072; (b)A. Y. Shaw, C. -Y. Chang, M. Y. Hsu, P. J. Lu, C. N.Yang, H. L. Chen, C. -W. Lo, C. W. Shiau and M. -K. Chern, European Journal of Medicinal Chemistry, 45, 2860(2010), DOI:10.1016/j.ejmech.2010.03.008; (c)K. K. Sivakumar, A. Rajasekaran, P. Senthilkumar and P. P. Wattamwar, Bioorganic Medicinal Chemistry Letters, 24, 2940(2014), DOI: 10.1016/j.bmcl.2014.04.067; (d)S. N. Pandeya, D. Sriram, G. Nath and E. D. Clercq, European Journal of Medicinal Chemistry, 35, 249(2000), DOI:10.1016/S0223-5234(00)00125-2; (e)S. S Kadu and G. V Korpe, Rasayan Journal of Chemistry, 9, 40(2016); (f)N. A. Bhise, S. A. Alhoraibi, S. T. Gaikwad and A. S. Rajbhoj, Rasayan Journal of Chemistry, 12, 101(2019), DOI: $10.31788 /$ RJC.2019.1214045.

25. B. Pacorel, S. C. Leung, A. V. Stachulski, J. Davies, L. Vivas, H. Lander, S. A. Wards, M. Kaiser, R. Brun and P. M. O. Niell, Journal of Medicinal Chemistry, 53, 633(2010), DOI:10.1021/jm901216v.

26. M. S. Khan, A. Husain and S. Sharma, Acta Poloniae Pharmaceuticals, 67, 261(2010).

27. L. Popiolek, J. Rzymowska, U. Kosikowska, A. Hordyjewska, M. Wujec and A. Malm, Journal of Enzyme Inhibition and Medicinal Chemistry, 29, 786(2014), DOI:10.3109/14756366.2013.855926.

28. S. Joshi, N. Khosla, D. Khare and R Sharda, Bioorganic Medicinal Chemistry Letters, 15, 221(2005), DOI: $10.1016 / \mathrm{j} . \mathrm{bmcl} .2004 .09 .084$.

29. B. L. Khalil, M. A. Younus, T. M. Salih, R. M. Rumez and B. W. Khamma, Chemistry and Materials Research, 6, 55(2014)

30. N. H. Jainab, P. Sivachidambaram, J. Yuvaraju, K. J. Beyatricks and B. Raj, Asian Journal of Research in Chemistry, 7, 176(2014).

31. G. Cihan-Ustundag, B. Simsek, E. Ilhan and G. Capan, Letters in Drug, Design and Discovery, 11, 290(2014), DOI: 10.2174/157018081131000074.

32. R. P. Purushottam, S. M. Vishal, V. K. Deshmukh and S. R. Chaudhari, International Journal of Pharmaceutical Science Review and Research, 21, 199(2013)

33. A. Zalai, in 5th Int. Koll. Addit. Schmierst. Arbeits Flussigkeiton, Budapest, 2, 91411(1986).

34. H. X. Feng, J. Li and X. H. Gao, Advanced Materials Research, 538, 2329(2012), DOI: 10.4028/www.scientific.net/AMR.538-541.2329.

35. M. Tramontini, L. Angiolini and N. Ghedini, Polymer, 29, 771(1988), DOI:10.1016/00323861(88)90132-2.

36. A. G. Khiratkar, K. R. Balinge, K. J. Bhansali and P. R. Bhagat, Research on Chemical Intermediate, ,44, 787(2018), DOI:10.1007/s11164-017-3134-x.

37. A. Davoodnia, A. Tavakoli-Nishaburi and N. Tavakoli-Hoseini, Bulletin of the Korean Chemical Society, 32, 635(2011), DOI:10.5012/bkcs.2011.32.2.635. 
RASĀYAN J. Chem.

Vol. 13 | No. 3 |1842-1852 | July - September | 2020

38. H. Li, H. Y. Zeng and H. W. Shao, Tetrahedron Lett., 50, 6858(2009), DOI:10.1016/j.tetlet.2009.09.131.

39. S. Iimura, D. Nobutou, K. Manabe and S. Kobayashi, Chemical Communications, 1644(2003), DOI: $10.1039 / \mathrm{B} 304343 \mathrm{~F}$.

40. S. Ramalingam and P. Kumar, Catalysis Communications, 9, 2445(2008), DOI: $10.1016 /$ j.catcom.2008.06.011.

41. N. Azizi, L. Torkiyan and M. R. Saidi, Organic Letters, 8, 2079(2006), DOI:10.1021/ol060498v.

42. R. Kurane, J. Jadhav, S. Khanapure, R Salunkhe and G. Rashinkar, Green Chemistry, 15, 1849(2013), DOI: $10.1039 / \mathrm{C} 3 \mathrm{GC} 40592 \mathrm{C}$.

43. A. Naikwade, M. Jagadale, D. Kale, S. Gajare and G. Rashinkar, Catalysis Letters, 148, 3178(2018), DOI: $10.1007 / \mathrm{s} 10562-018-2514-1$.

44. K. Kundu and S. K. Nayak, RSC-Advances, 2, 480(2012), DOI:10.1039/C1RA00652E.

45. H. Li, H. Zeng and H. Shao, Tetrahedron Letters, 50,6858(2009), DOI: $10.1016 /$ j.tetlet.2009.09.131.

46. R. Wang, B. Li, T. Huang, L. Shi and X. Lu, Tetrahedron Letters, 48, 2071(2007), DOI:10.1016/j.tetlet.2007.01.142.

47. F. Nemati, M. A. Bigdeli, G. H. Mahdavini and H. Kiani, Green Chemistry Letters and Reviews, 2, 89 (2010), DOI:10.1080/17518250903567253.

48. H. B. Wang, N. Yao, L. Wang and Y. L. Hu, New Journal of Chemistry, 41, 10528(2017), DOI: $10.1039 / \mathrm{C} 7 \mathrm{NJ} 02541 \mathrm{~F}$.

49. A. Davoodnia, A. T. Nishaburi and N. T. Hoseini, Bulletin of the Korean Chemical. Society, 32, 635(2011), DOI: 10.5012/bkcs.2011.32.2.635.

50. S. Sahoo, T. Joseph and S. B. Halligudi, Journal of Molecular Catalysis A: Chemical, 244, 179(2006), DOI: $10.1016 /$ j.molcata.2005.09.012

51. A. Teimouri, A. N. Chermahini and L Ghorbanian, Bulgarian Chemical Communications, 46, 523(2014).

[RJC-5758/2020] 